\title{
Characterization of TNAZ
}

\author{
R.L. Simpson, R.G. Garza, M.F. Foltz \\ D.L. Ornellas, and P.A. Urtiew \\ Energetic Materials Center \\ Lawrence Livermore National Laboratory \\ Livermore, CA 94550
}

December 14, 1994

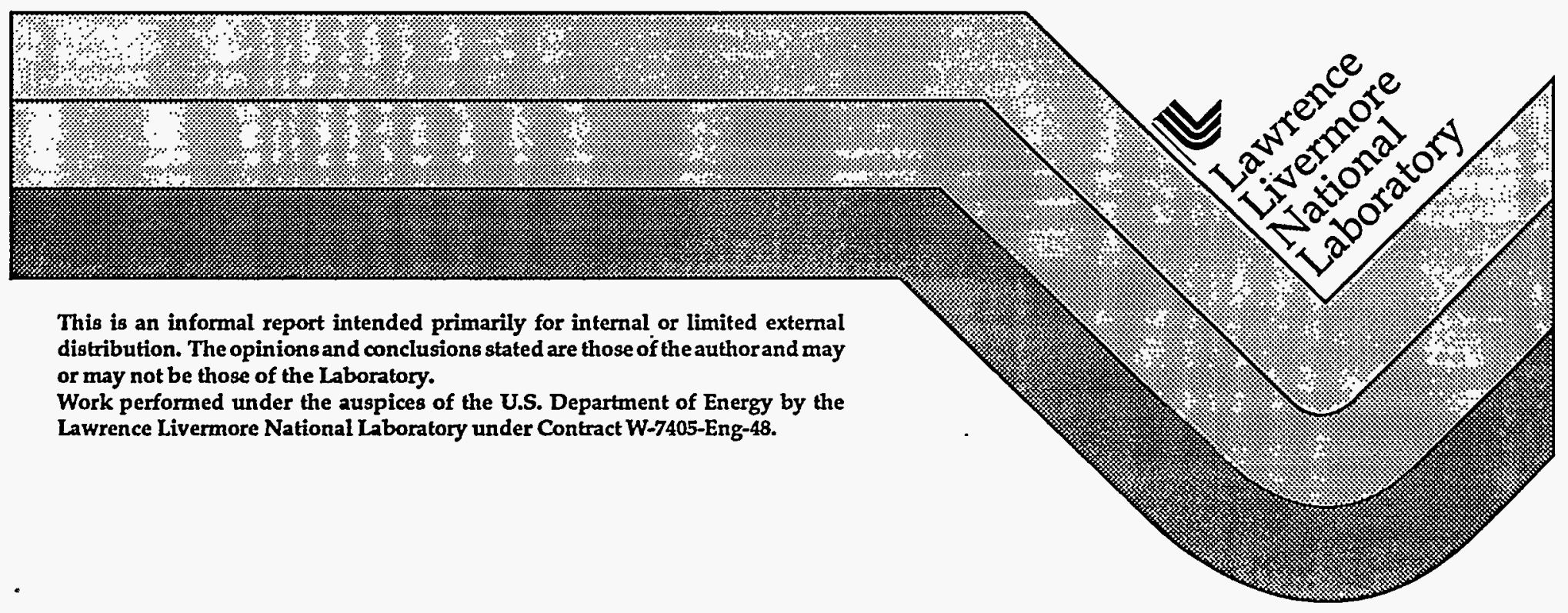




\section{DISCLAIMER}

This document was prepared as an account of work sponsored by an agency of the United States Government. Neither the United States Covernment nor the University of California nor any of their employees, makes any warranty, express or implied, or assumes any legal liability or responsibility for the accuracy, completeness, or usefulness of any information, apparatus, product, or process disclosed, or represents that its use would not infringe privately owned rights. Reference herein to any specific commercial product, process, or service by trade name, trademark, manufacturer, or otherwise, does not necessarily constitute or imply its endorsement, recommendation, or favoring by the United States Government or the University of California. The views and opinions of authors expressed herein do not necessarily state or reflect those of the United States Government or the University of California, and shall not be used for advertising or product endorsement purposes.

This report has been reproduced directly from the best available copy.

Available to DOE and DOE contractors from the Office of Scientific and Technical Information

P.O. Box 62, Oak Ridge, TN 37831

Prices available from (615) 576-8401, FTS 626-8401

Available to the public from the National Technical Information Service

U.S. Department of Commerce 5285 Port Royal Rd. Springfield, VA 22161 


\section{DISCLAIMER}

Portions of this document may be illegible in electronic image products. Images are produced from the best available original document. 


\title{
Characterization of TNAZ
}

\author{
R.L. Simpson, R.G. Garza, M.F. Foltz, D.L. Ornellas and P.A. Urtiew
}

(510) 423-0379

\section{Summary}

The explosive TNAZ has recently become available in pilot-plant quantities. We have found its small-scale safety properties similar to those of other nitramines. Detonation calorimetry showed TNAZ to have $96 \%$ the energy of HMX and $150 \%$ of TNT. The shock sensitivity of neat TNAZ is greater than LX-14. A retonation wave was observed when the material was shocked at $2.0 \mathrm{GPa}$. The initiation behavior of neat TNAZ cannot be classified as either homogeneous or heterogeneous. Six plastic bonded TNAZ-based explosives have been developed for the Army.

\section{Introduction}

Archibald synthesized the four-membered ring explosive 1,3,3-trinitroazetidine (TNAZ) in 1990.1 This material may be of importance to the energetic materials community for several reasons. It has an energy density nearly that of the standard high energy explosive HMX.2 Unlike most nitramines it has a melt transition without decomposition at $\approx 100^{\circ} \mathrm{C}$. Hence, melt casting may be possible. 3,4 In addition, it has been hypothesized by us that the low temperature melt phase may enhance the resistance of a TNAZ-based explosive or propellant to form hot spots (leading to initiation) during mechanical loading. Thus, even though the performance of TNAZ is slightly less than HMX (in metal acceleration TNAZ and HMX are comparable, however, calorimetrically and in metallized systems the energy of TNAZ is lower) it may be less vulnerable in practical applications. Finally, the oxygen balance is greater than that of HMX and the detonation products are hot, making it attractive as an ingredient in composite explosives.<smiles>O=[N+]([O-])N1CC([N+](=O)[O-])([N+](=O)[O-])C1</smiles>

\section{1,3,3-Trinitroazetidine (TNAZ).}

We have examined the small-scale safety properties, calorimetric heat, thermal explosion behavior, and sensitivity to shock of TNAZ. All materials used were synthesized by GenCorp Aerojet (Sacramento). We have received three quantities of TNAZ referred to hereafter as: C144, C167, and C168. The later two samples were 
provided by the Wright Laboratory at the Eglin Air Force Base. The C168 material was recrystallized by S. Aubert at Eglin.

\section{Small-Scale Sensitivity of TNAZ}

Table 1 summarizes the small-scale safety data obtained with TNAZ. The impact sensitivity was found to be similar to that of HMX. The impact response determined for C144 was very good, although, the purity is uncertain. Significant out-gassing was seen with the Chemical Reactivity Test (CRT). The impurity lowered the onset of the principal exotherm by $13^{\circ} \mathrm{C}$ but had little effect on the melting point. In contrast to the impact response the apparent friction sensitivity, as determined by the BAM method, showed purer TNAZ to be somewhat less sensitive.

Table 1. Small-scale sensitivity test results.

\begin{tabular}{|c|c|c|c|c|c|}
\hline Material & $\begin{array}{c}\text { Impacta } \\
(\mathrm{cm})\end{array}$ & $\begin{array}{c}\mathrm{CRT}^{\mathrm{b}} \\
(\mathrm{cc} / 0.25 \mathrm{~g})\end{array}$ & $\begin{array}{c}\text { DSCC } \\
\left({ }^{\circ} \mathrm{C}\right)\end{array}$ & $\overline{\text { Spark }}$ & $\begin{array}{c}\text { Frictione } \\
(\mathrm{kg})\end{array}$ \\
\hline Aerojet (C144) & 86 & 0.635 & m.p. $\approx 99.45 ; 232$ & no rxn & 5.4 \\
\hline Eglin (C167) & 29 & 0.045 & m.p. $\approx 99.36 ; 243$ & no rxn & 8.0 \\
\hline Eglin (C168) & 28 & 0.049 & m.p. $\approx 96.83 ; 245$ & no rxn & 11.6 \\
\hline HMX ref. & 32 & $\leq 0.2$ & 270 & no $\mathrm{rxn}$ & 11.6 \\
\hline
\end{tabular}

a $2.5 \mathrm{~kg}$, Type $12 \mathrm{~A}, 35 \mathrm{mg}$ pressed pellets.

b Chemical reactivity test. $120^{\circ} \mathrm{C}$ for $22 \mathrm{~h}$ under $1 \mathrm{~atm} \mathrm{He}$.

c $10^{\circ} \mathrm{C} / \mathrm{min}$; maximum of endothermic response and onset of exotherm.

d $1 \mathrm{~J}$ with $510 \Omega$.

e BAM.

Differential scanning calorimetry measurements were made on all materials. Figure 1 displays thermal properties between ambient and $350^{\circ} \mathrm{C}$. As listed in Table 1 a melt transition occurs at $\approx 99^{\circ} \mathrm{C}$. The calorimetric measurements were made with perforated sample pans to vent the decomposition products. The gradual endothermic behavior observed after the melt transition can be explained as latent heat. The principal exotherm is $245^{\circ} \mathrm{C}$ for pure TNAZ versus $270^{\circ} \mathrm{C}$ for $\mathrm{HMX}$. 

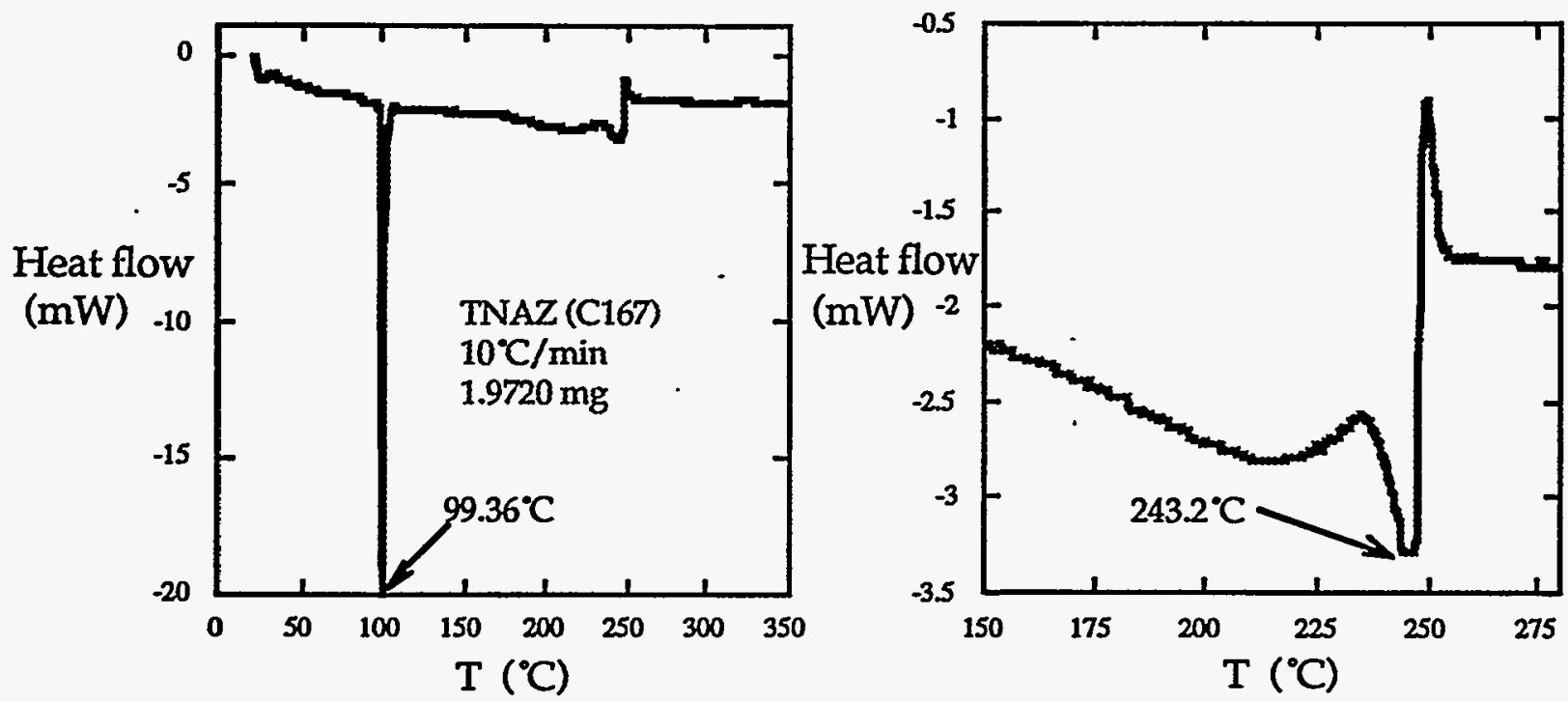

Figure 1. Differential scanning calorimetry traces of TNAZ. $10^{\circ} \mathrm{C} / \mathrm{min}$.

One-dimensional-time-to-explosion (ODTX) experiments were run from which a thermal response model can be established. The time between sample insertion and explosion is determined for a range of temperatures down to the critical temperature below which no reaction occurs. Spheres of TNAZ $(12.7 \mathrm{~mm}$ dia.) are rapidly place in a preheated aluminum cavity. The aluminum-TNAZ boundary is maintained at isothermal conditions. Mechanical sample confinement was approximately $0.15 \mathrm{GPa}$ for all experiments. Neat TNAZ samples were pressed to $97-99 \%$ of theoretical maximum density using a spherical die set.

The results of ODTX experiments on TNAZ are shown in Fig. 2. Figure 2a plots the data as the logarithm of time-to-explosion vs. inverse temperature. The time-toexplosion response of TNAZ is similar to RDX and $\varepsilon-C L-20$ at moderate and higher temperatures. At low temperature the time response approaches that of HMX. All reactions observed with TNAZ were violent; perhaps detonations. Reactions at intermediate temperatures were most violent as is often observed with other materials.

It can be seen in Fig. $2 a$ that the slope of $\log _{10}(t)$ vs. $1 / T$ is not constant. The slope of this line is proportional to the chemical activation energy. At moderate to high temperatures the activation energy of TNAZ is less than other common materials. At lower temperatures the slope is higher and the temperature dependence on the time to explosion is greater.

Figure $2 \mathrm{~b}$ shows the ODTX data plotted linearly. It can be seen that minimum temperature required for explosive decomposition is $\approx 201^{\circ} \mathrm{C}$. Temperatures just $2^{\circ} \mathrm{C}$ below $201^{\circ} \mathrm{C}$ were inadequate to obtain explosion in the ODTX configuration. This ODTX critical temperature is higher than those of the other nitramines HMX, RDX, and $\varepsilon-C L-20$. These data are consistent with the slow and fast cookoff tests of Aubert ${ }^{2}$ where he observed detonations occurring at sample temperatures from $198-214^{\circ} \mathrm{C}$. 


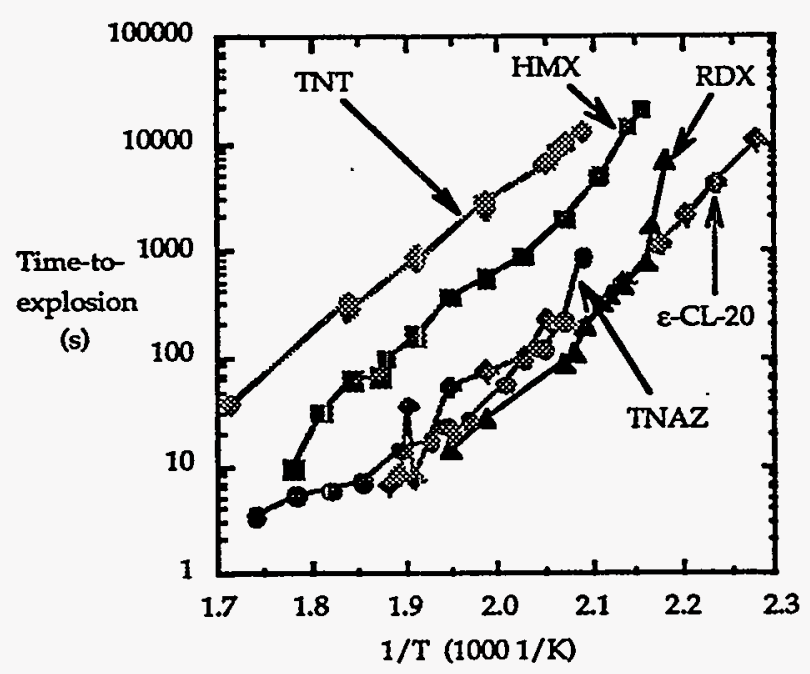

(a)

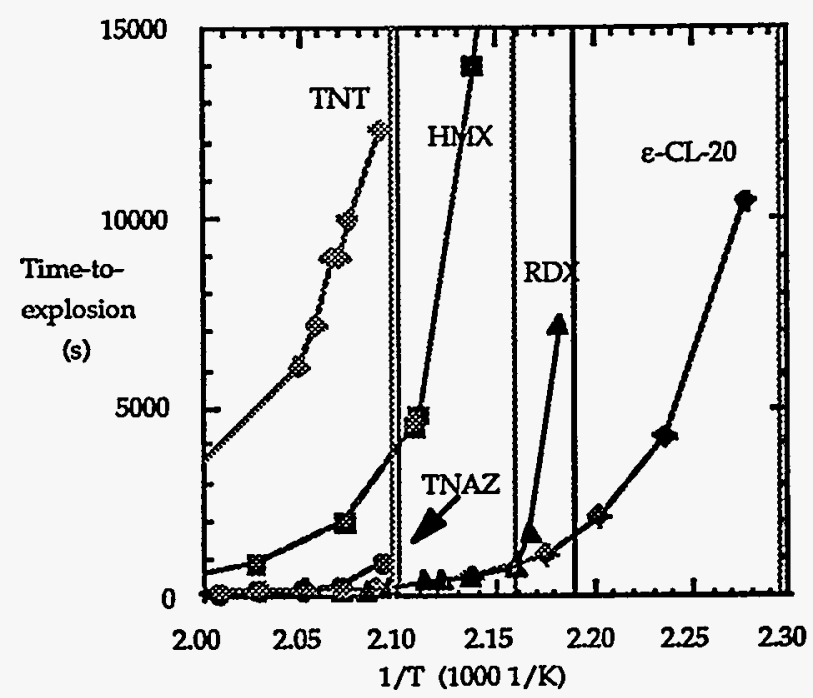

(b)

Figure 2. (a) The times to explosive reaction with TNAZ are similar to those of RDX and $\varepsilon-C L-20$. (b) The critical temperature of TNAZ is much higher than those of other nitramines. $\mathrm{T}_{\mathrm{c}}$ : TNT, $203^{\circ} \mathrm{C}$; TNAZ, $201^{\circ} \mathrm{C} ; \mathrm{HMX}, 190^{\circ} \mathrm{C}$; RDX, $184^{\circ} \mathrm{C}$; $\varepsilon-\mathrm{CL}-20 ; 163^{\circ} \mathrm{C}$.

\section{Combustion and Detonation Calorimetry}

To advance thermochemical predictions of detonation performance and equations of state, accurate values of the molecular heats of formation $\left(\Delta \mathrm{H}_{\mathrm{f}}\right)$ are required. TNAZ is particularly important scientifically in that it is one of the few materials in which precise detonation physics experiments can be carried out at near crystal density without the use of binders or plasticizers. Our theoretical predictions of the explosive performance of TNAZ overpredict that observed when the generally reported $\Delta \mathrm{H}_{\mathrm{f}}$ of $8.7 \mathrm{kcal} / \mathrm{mol}$ is used for which the pedigree is not known. Therefore, we have carried out combustion calorimetry experiments on TNAZ to determine $\Delta \mathrm{H}_{\mathrm{f}}$.

A Parr isothermal calorimeter was used to determine the heat of combustion. TNAZ sample purity (C167) was evaluated by subliming material and performing qualitative and quantitative analyses on both the sublimed and unsublimed materials. The melting points of the C167 and sublimed TNAZ samples were respectively; 99.5$100.5^{\circ} \mathrm{C}$ and $99.4-100.4^{\circ} \mathrm{C}$. Purity of the samples were examined via high pressure liquid chromatography, gas chromatography/mass spectrometry, direct inlet probe mass spectrometry, and infrared spectroscopy. From these test results we conclude that C167 is $\geq 99.8 \%$ pure TNAZ.

Replicate runs with $1.5 \mathrm{~g}$ pressed pellets burned cleanly under standard conditions leaving no visible residue. The $\Delta \mathrm{H}_{\mathrm{f}}$ result and the estimated uncertainty are listed in Table 2. The Washburn correction reducing the data to standard states was not done. Our value is $5.9 \mathrm{kcal} / \mathrm{mol}$ less than that previously reported. We have a high degree of confidence in the new $\Delta \mathrm{H}_{\mathrm{f}}$ value. 
Table 2. Measured $\Delta \mathrm{H}_{\mathrm{f}}$ of TNAZ in this work.

\begin{tabular}{|l|c|}
\hline \hline Origin & $\begin{array}{c}\Delta \mathrm{H}_{\mathrm{f}} \\
(\mathrm{kcal} / \mathrm{mol})\end{array}$ \\
\hline This work (C167) & $+2.81 \pm 1$ \\
\hline Generally reported value & +8.7 \\
\hline \hline
\end{tabular}

Detonation calorimetry 5 on pure TNAZ was performed. The energy density determined in this experiment represents the energy difference between TNAZ at ambient conditions and its detonation products. A $1.27 \mathrm{~cm}$ diameter cylinder of TNAZ weighing $26.4 \mathrm{~g}$ at $99.6 \%$ of theoretical maximum density was confined in a gold annulus having a $1.27 \mathrm{~cm}$ wall thickness. The heavy inertial confinement by the gold minimizes reshock and, hence, a shift in chemical equilibrium, allowing the product expansion to occur along the Chapman-Jouguet isentrope. The TNAZ was initiated with $0.25 \mathrm{~g}$ of PETN in a $65 \mathrm{~Pa}$ vacuum.

Table 3 lists the detonation calorimetry results. The $\Delta \mathrm{H}_{\text {det }}$ was determined to be $1466 \mathrm{cal} / \mathrm{g}$. Only a trace amount of solid carbon was recovered. A unique aspect of this calorimetric experiment was a gold hue left on the inside of bomb resulting from vaporization of part of the gold annulus.

Table 3. Detonation calorimetry results with C167 TNAZ.

\begin{tabular}{|l|c|}
\hline \hline Sample density & $1.83 \mathrm{~g} / \mathrm{cc}$ \\
\hline Percent of theoretical maximum density & $99.6 \%$ \\
\hline Sample mass & $26.4 \mathrm{~g}$ \\
\hline$-\Delta \mathrm{H}_{\text {detonation }}$ - experimental & $1464 \pm 15 \mathrm{cal} / \mathrm{g} \quad(6130 \mathrm{~J} / \mathrm{g})$ \\
\hline $\begin{array}{c}-\Delta \mathrm{H}_{\text {detonation }} \text { - calculated from } \\
\text { products at } 298 \mathrm{~K}, \mathrm{H}_{2} \mathrm{O}_{(\mathrm{l})}\end{array}$ & $1520 \pm 100 \mathrm{cal} / \mathrm{g} \quad(6364 \mathrm{~J} / \mathrm{g})$ \\
\hline \hline Detonation products $(\mathrm{mole} /$ mole HE) & Measured \\
\hline $\mathrm{N}_{2}$ & 1.88 \\
\hline $\mathrm{H}_{2} \mathrm{O}$ & 1.54 \\
\hline $\mathrm{CO}_{2}$ & 1.52 \\
\hline $\mathrm{CO}_{2}$ & 1.30 \\
\hline $\mathrm{H}_{2}$ & 0.25 \\
\hline $\mathrm{NH}_{3}$ & 0.14 \\
\hline $\mathrm{HCN}$ & 0.017 \\
\hline $\mathrm{CH}$ & 0.015 \\
\hline $\left.\mathrm{C}_{4} \mathrm{~S}\right)$ & Trace present \\
\hline $\mathrm{C}$ & Measured \\
\hline \hline Material recovery (mole $\%)$ & $94.9 \%$ \\
\hline $\mathrm{H}$ & 102 \\
\hline $\mathrm{N}$ & 97.9 \\
\hline $\mathrm{O}$ & 97.8 \\
\hline \hline
\end{tabular}


A comparison of the energy densities of common explosives is given in Table 4. The highest energy density material ever measured is hexanitrobenzene (HNB). The next highest is $\varepsilon-C L-20$. The energy density of TNAZ is $106 \mathrm{cal} / \mathrm{cc}$ (4\%) less than HMX and $58 \mathrm{cal} / \mathrm{cc}(2 \%)$ more than PETN. More significant is that the energy of TNAZ is $150 \%$ that of TNT. Hence, if processes can be developed that take advantage of the melt phase of TNAZ and enable it to be used where current technologies are limited to TNT, significant improvements in energy will be realized.

Table 4. Detonation energies of a number of explosives. The energy density of TNAZ is $100 \mathrm{cal} / \mathrm{cc}$ less than that of HMX.

\begin{tabular}{|l|c|c|c|c|c|}
\hline \hline Explosive & $\begin{array}{c}\text { Density } \\
\text { (g/cc) }\end{array}$ & $\begin{array}{c}\text { Energy } \\
\text { (cal/g) }\end{array}$ & $\begin{array}{c}\text { Energy } \\
\text { density } \\
\text { (cal/cc) }\end{array}$ & $\begin{array}{c}\text { Energy density at } \\
\text { maximum density } \\
\text { (cal/cc) }\end{array}$ & $\begin{array}{c}\text { Energy density } \\
\text { relative to } \\
\text { HMX }\end{array}$ \\
\hline HNBa & 1.92 & 1650 & 3170 & 3251 & $115 \%$ \\
\hline$\varepsilon-$ CL-20 & 1.96 & 1500 & 2940 & 3060 & 109 \\
\hline HMX & 1.89 & 1480 & 2797 & 2816 & 100 \\
\hline TNAZ & 1.83 & 1465 & 2696 & 2710 & 96 \\
\hline PETN & 1.73 & 1490 & 2580 & 2652 & 94 \\
\hline TNT & 1.53 & 1090 & 1670 & 1803 & 64 \\
\hline \hline
\end{tabular}

a HNB is hexanitrobenzene.

\section{Shock Loading}

We have carried out three shock loading experiments on neat TNAZ. The configuration of the experiments is shown in Fig. 3. Six manganin gauges were located at three positions in $9.0 \mathrm{~cm}$ dia. $\times 3.0 \mathrm{~cm}$ long TNAZ samples. A sabot of $6061-\mathrm{T} 6$ aluminum impacts a buffer plate driving a shock wave through the sample. Pressure histories are recorded at each of the three locations. In addition, shock transit times are measured between gauge locations. At low pressures the shock wave may be treated as unsupported by chemical reaction and the Rankine-Hugoniot equations used to determine the non-reactive Hugoniot of TNAZ. 


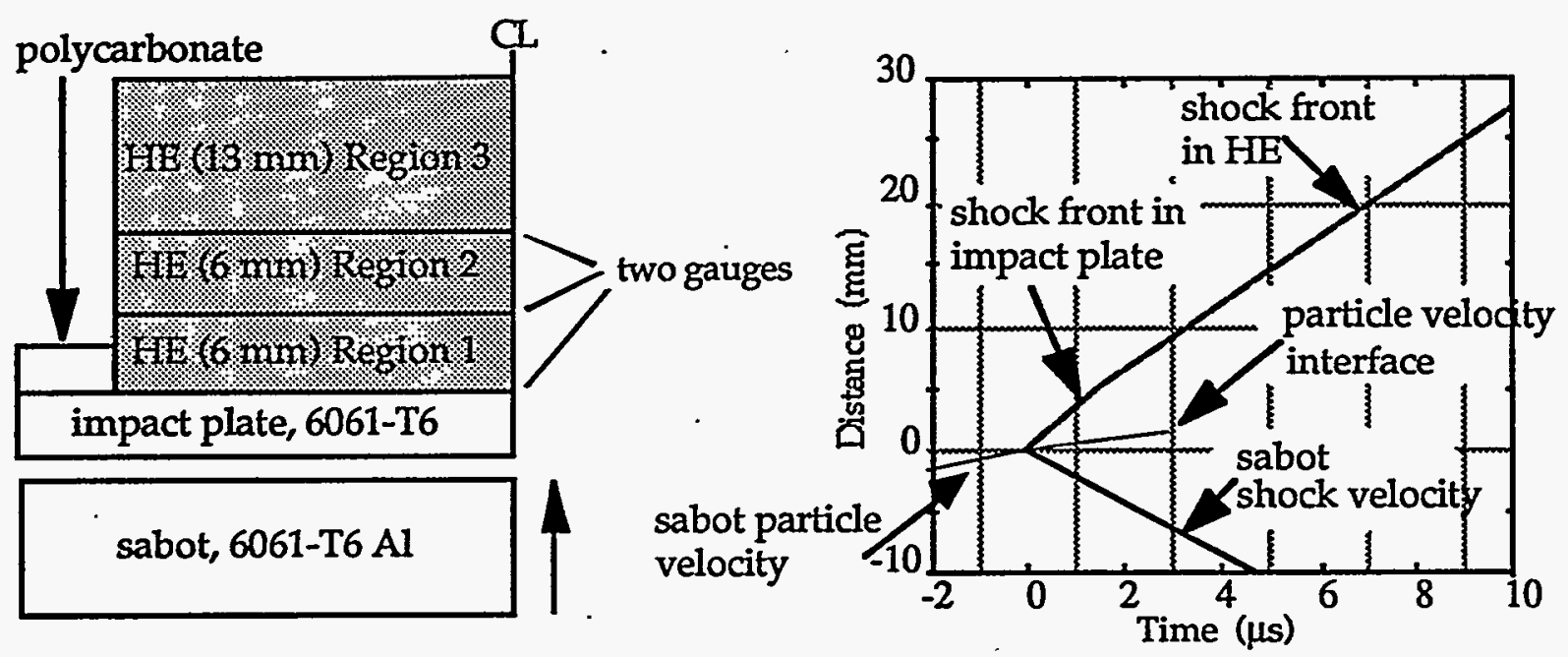

Figure 3. Shock loading configuration. The gauge locations are at sample depths of $0 \mathrm{~mm}, 6.5 \mathrm{~mm}$, and $13 \mathrm{~mm}$.

Table 5 summarizes the Hugoniot data obtained with TNAZ. The three experiments carried out shock loaded samples to $1.3 \mathrm{GPa}, 2.0 \mathrm{GPa}$ and $3.6 \mathrm{GPa}$. As will be discussed at $3.6 \mathrm{GPa}$ the initial shock wave may not be treated as inert. At $2.0 \mathrm{GPa}$ a $2 \%$ faster shock velocity is observed in Region 2 compared to Region 1 . This can be accounted for as the result of a greater density of the TNAZ sample. However, as will be seen, with an input shock strength of $2.0 \mathrm{GPa}$, TNAZ is near detonation as the shock wave transits Region 2 . Thus, the faster velocity in Region 2 may also be due, in part, to a reaction supported shock front.

Table 5. Shock Hugoniot data. Exp. 2 had a faster shock velocity in Region 2 indicating a reaction supported shock. Hence, only Exp. 1 and Exp. 2 - Region 1 should be considered unreactive.

\begin{tabular}{|l|c|c|c|c|c|c|c|c|}
\hline \hline Experiment & $\begin{array}{c}\mathrm{V}_{\mathrm{f}} \\
(\mathrm{mm} / \mu \mathrm{s})\end{array}$ & $\begin{array}{c}\rho_{\mathrm{o}} \\
(\mathrm{g} / \mathrm{cc})\end{array}$ & $\begin{array}{c}\mathrm{u}_{\mathrm{p}} \\
(\mathrm{mm} / \mu \mathrm{s})\end{array}$ & $\begin{array}{c}\mathrm{U}_{\mathrm{s}} \\
(\mathrm{mm} / \mu \mathrm{s})\end{array}$ & $\begin{array}{c}\mathrm{P} \\
(\mathrm{GPa})\end{array}$ & $\begin{array}{c}\mathrm{V} \\
(\mathrm{cc} / \mathrm{g})\end{array}$ & $\mathrm{V} / \mathrm{Vo}$ & $\begin{array}{c}\rho \\
(\mathrm{g} / \mathrm{cc})\end{array}$ \\
\hline 1, Regions 1\& 2 & 0.352 & 1.813 & 0.263 & 2.76 & 1.31 & 0.499 & 0.9045 & 2.00 \\
\hline 2, Region 1 & 0.483 & 1.802 & 0.350 & 3.14 & 1.98 & 0.493 & 0.888 & 2.03 \\
\hline 2, Region 2 & 0.483 & 1.835 & 0.3465 & 3.21 & 2.04 & 0.481 & 0.8925 & 2.06 \\
\hline $3^{\mathrm{a}}$, Region 1 & 0.684 & 1.831 & 0.448 & 4.42 & 3.61 & 0.491 & 0.899 & 2.04 \\
\hline
\end{tabular}

a Reaction supported shock likely.

The measured pressured histories are shown in Figs. 4-6. At 1.3 GPa (Fig. 4) no buildup in pressure was observed. At $2.0 \mathrm{GPa}$, Fig. 5, a very different phenomenon was seen. A gradual pressure buildup occurred at gauge location 1. The reaction rate is faster $6.5 \mathrm{~mm}$ into the sample. At $13 \mathrm{~mm}$ the sample is nearly detonating. Secondary shock fronts also can be observed on the records of gauges 1 and 2 at late times. This is the first time that this behavior has been observed with in situ gauges.

What appears to be happening is that there is a very nonlinear growth of reaction in shocked TNAZ. Most condensed phase explosive initiation can be described as either homogeneous or heterogeneous. In homogeneous initiation an inert shock wave moves 
through the sample. At the point at which the shock entered the explosive a transition to detonation occurs and the detonation front travels through the preshocked region and overtakes the initial shock wave. In heterogeneous initiation the shock strength increases as it moves through the explosive until a steady state detonation occurs. Significant decomposition occurs behind the shock front and there is inadequate energy to produce a rearward moving shock.

In the case of TNAZ there is little growth of reaction behind the shock front. In the 2.0 GPa experiment after the shock reaches gauge station 3 the detonation occurs within Region 2 and forward and rearward moving shocks reach gauge stations 2 and 3 at nearly equivalent times. The rearward moving shock wave reaches gauge station 1 approximately $850 \mathrm{~ns}$ later. The retonation wave velocity in Region 1 is $7.5 \mathrm{~mm} / \mu \mathrm{s}$. Aubert ${ }^{2}$ measured a steady state detonation velocity of TNAZ in a cylinder test of $8.73 \mathrm{~mm} / \mu \mathrm{s}$. The lower retonation velocity is consistent with TNAZ partially reacting after the first shock wave.

Figure 6 supports the conclusion of a retonation. With a shock input of $3.6 \mathrm{GPa}$ a detonation front was reached at gauge station 2 . The shock velocity was $8.24 \mathrm{~mm} / \mu \mathrm{s}$ which is $0.49 \mathrm{~mm} / \mu$ s less than observed at steady state suggesting that the buildup was not complete at gauge station 2 . The first gauge shows two regions of buildup; the first is slow, the second very fast. This is consistent with the retonation observed in Fig. 5 where there was very slow growth in pressure followed by a shock. At the higher input pressure of $3.6 \mathrm{GPa}$ the faster reaction rate after the shock transits the sample may prevent the formation of a retonation wave.

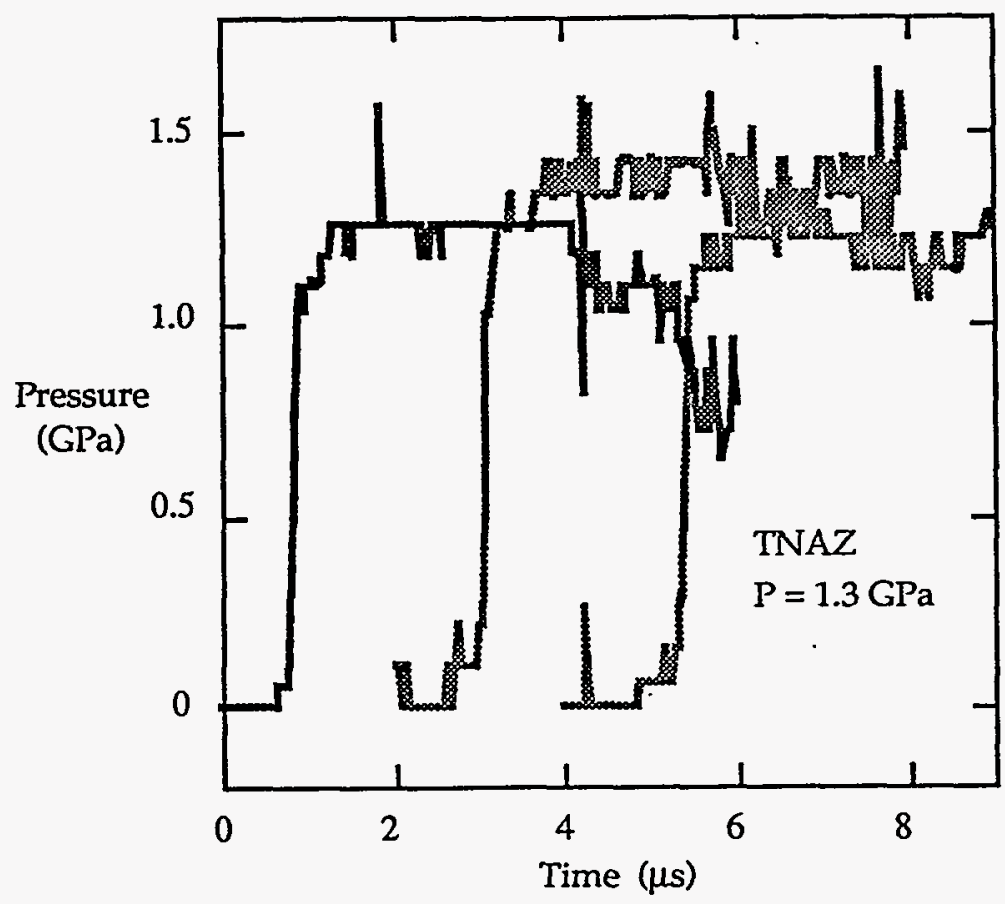

Figure 4. Neat TNAZ shock loaded to $1.3 \mathrm{GPa}$. 


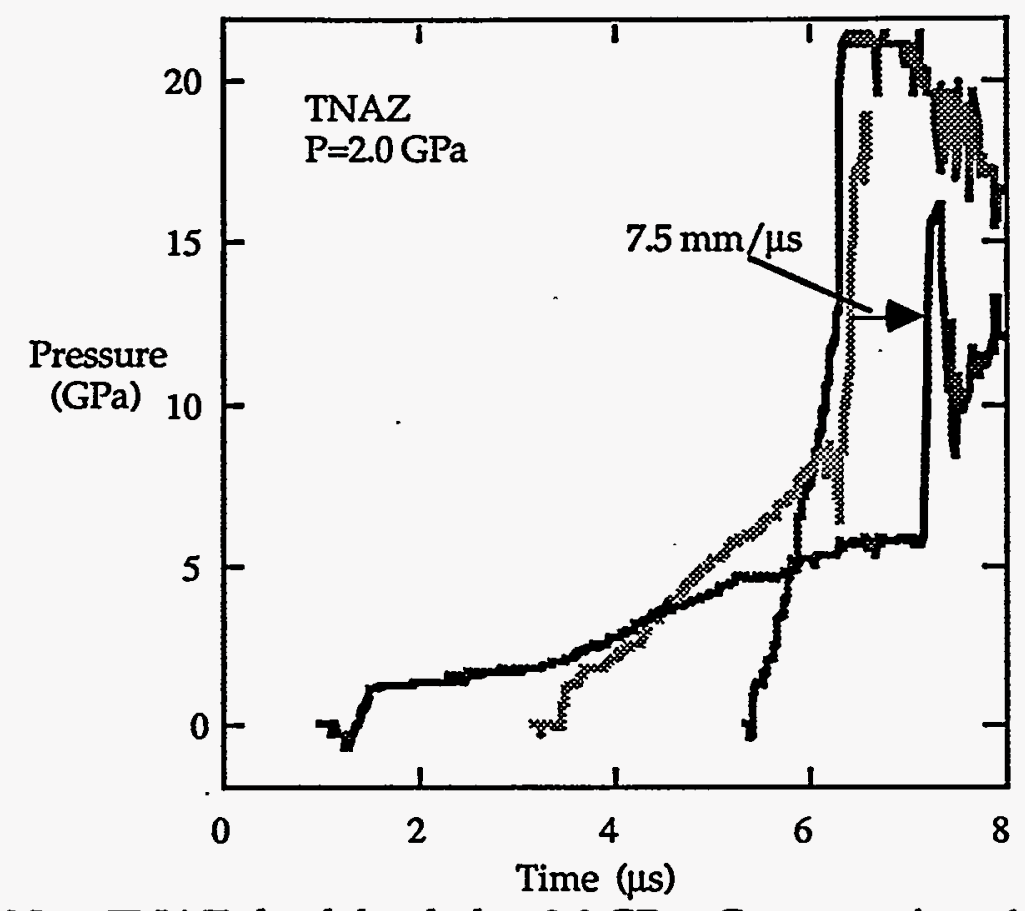

Figure 5. Neat TNAZ shock loaded to $2.0 \mathrm{GPa}$. Gauge stations 1 \& 2 indicate that a retonation may have occurred.

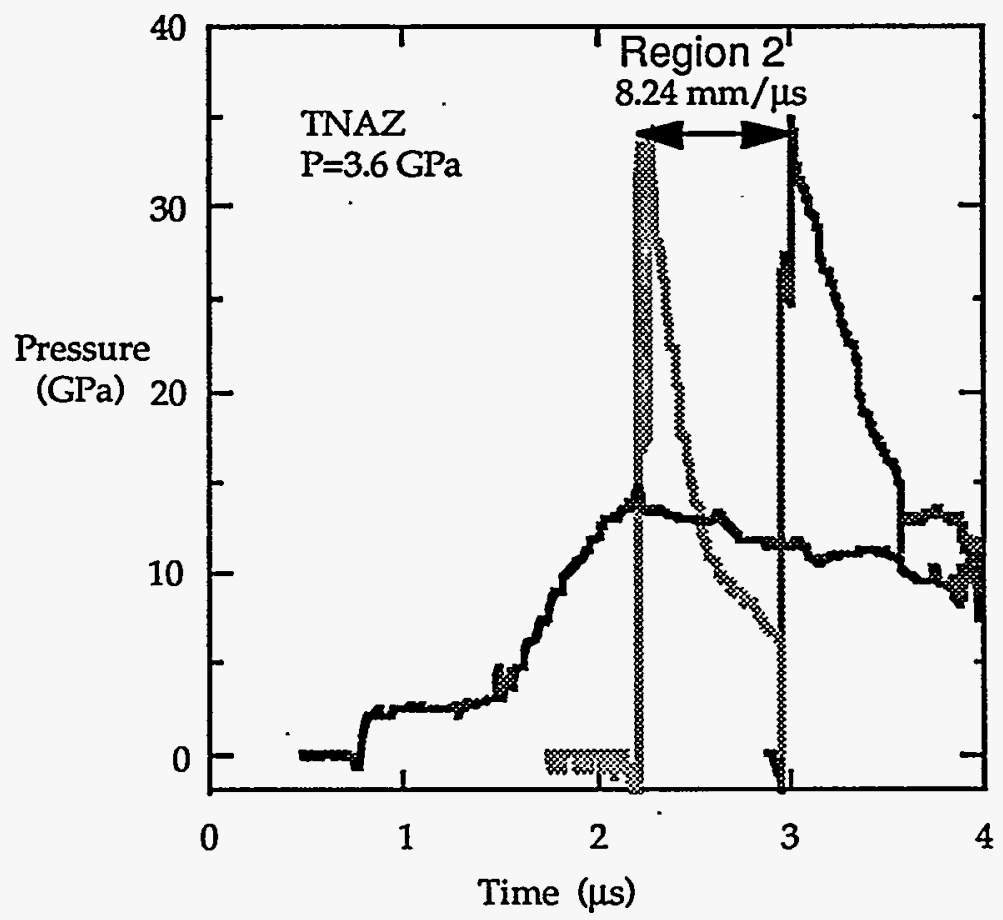

Figure 6. Neat TNAZ shock loaded to $3.6 \mathrm{GPa}$. Gauge station 1 displays a region with two apparent growth rates which is consistent with the retonation seen in Fig. 5 where the shock input pressure was $2.0 \mathrm{GPa}$. 
Figure 7 compares the shock behavior of the standard high energy explosive LX-14 with that of TNAZ. Each experiment was carried out in equivalent geometries. Input pressures were $2.0 \mathrm{GPa}$ and $2.27 \mathrm{GPa}$ with TNAZ and LX-14 respectively. Ignoring the more complicated initiation processes in TNAZ it can be seen that buildup rates are faster in TNAZ. In the TNAZ experiment after the shock wave has transited $13 \mathrm{~mm}$ it has nearly built to detonation unlike LX-14.

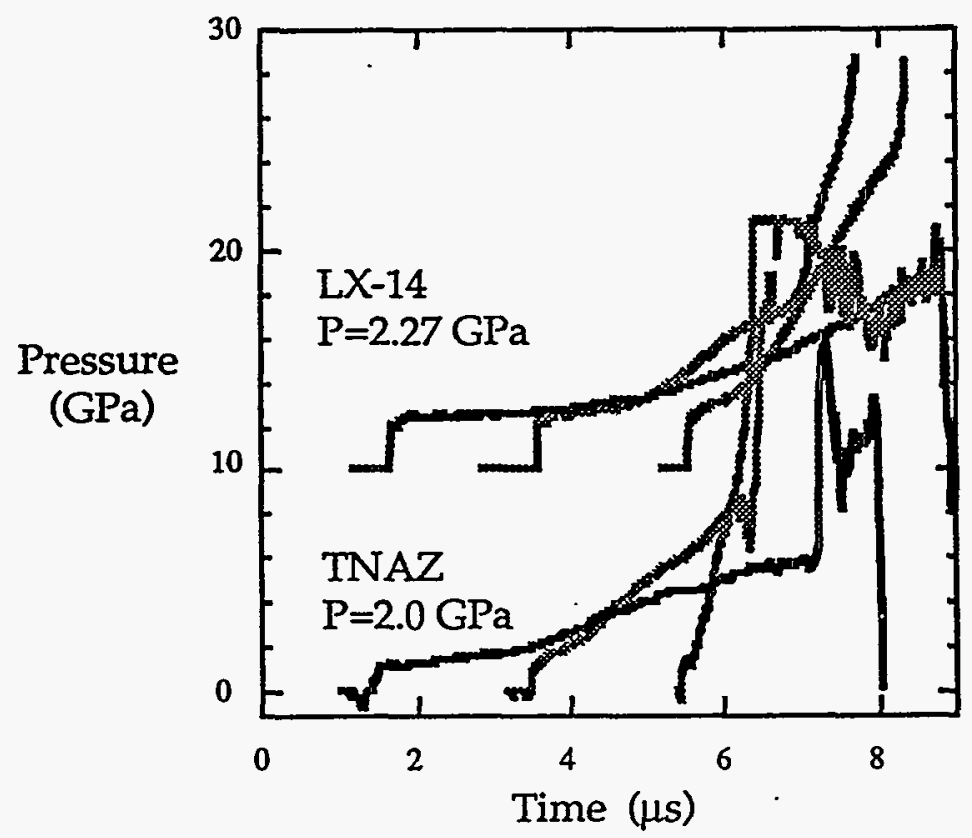

Figure 7. A comparison in sensitivity with $L X-14$ in the same experimental configuration shows TNAZ to be moderately more sensitive.

\section{Plastic Bonded TNAZ Formulations}

Although TNAZ presses beautifully without binder, the parts have poor mechanical integrity. We were requested by ARDEC to develop some plastic bonded TNAZ based explosives for shaped charge applications. The goal is to develop a material with significantly better mechanical properties using a minimum amount of binder. Mechanical property measurements are to be made by ARDEC.

Six materials have been made to date using three binders. The binders used were Viton A, Estane 5703P, and Fluorel L-9035. Formulations were prepared by the inverse slurry technique. Table 6 lists the formulations made and corresponding small-scale properties. The presence of binders increased the friction sensitivity over neat TNAZ as determined by the BAM method. Neither the Estane or Fluorel binders modified the impact sensitivity. The formulations containing Viton A actually displayed increased impact sensitivity over neat TNAZ. The Estane shows significant decomposition at $120^{\circ} \mathrm{C}$ in the CRT. This is typical with this polyester binder but its stability is acceptable for production explosives. 
Table 6. Small-scale sensitivity test results.

\begin{tabular}{|c|c|c|c|c|c|c|}
\hline Materiala $^{\mathrm{a}}$ & $\begin{array}{l}\text { TMD }^{b} \\
(g / c c)\end{array}$ & $\begin{array}{c}\text { Impactc } \\
(\mathrm{cm})\end{array}$ & $\begin{array}{c}\text { CRTd } \\
\text { (cc/0.25 g) }\end{array}$ & $\begin{array}{l}\text { DSCe } \\
\left({ }^{\circ} \mathrm{C}\right)\end{array}$ & Spark ${ }^{f}$ & $\begin{array}{l}\text { Frictiong } \\
(\mathrm{kg})\end{array}$ \\
\hline $\begin{array}{l}\text { RX-22-AT } \\
5 w t \% \text { Viton A }\end{array}$ & 1.839 & 26 & 0.037 & $\begin{array}{l}\text { m.p. } \approx 96.1 \\
\text { dec. } \approx 210\end{array}$ & no rx́n & $\overline{7.0}$ \\
\hline $\begin{array}{l}\text { RX-22-AU } \\
\text { 1wt\% Viton A }\end{array}$ & 1.840 & 22.5 & 0.050 & $\begin{array}{l}\text { m.p. } \approx 95.7 \\
\text { dec. } \approx 200\end{array}$ & no rxn & 7.2 \\
\hline $\begin{array}{l}\mathrm{RX-22- \textrm {AV }} \\
5 \mathrm{wt} \% \text { Estane }\end{array}$ & 1.790 & 30 & 0.382 & $\begin{array}{l}\text { m.p. } \approx 96.1 \\
\text { dec. } \approx 204\end{array}$ & no rxn & 7.6 \\
\hline $\begin{array}{l}\text { RX-22-AW } \\
\text { 1wt\% Estane }\end{array}$ & 1.830 & 28 & $\overline{0.230}$ & $\begin{array}{l}\text { m.p. } \approx 96.2 \\
\text { dec. } \approx 200 .\end{array}$ & no rxn & 6.4 \\
\hline $\begin{array}{l}\text { RX-22-AX } \\
5 w t \% \text { Fluorel }\end{array}$ & 1.841 & 31 & 0.046 & $\begin{array}{l}\text { m.p. } \approx 96.1 \\
\text { dec. } \approx 210\end{array}$ & no rxn & 6.4 \\
\hline $\begin{array}{l}\mathrm{RX}-22-\mathrm{AY} \\
\text { 1wt\% Fluorel }\end{array}$ & 1.840 & 28 & 0.125 & $\begin{array}{l}\text { m.p. } \approx 96.1 \\
\text { dec. } \approx 235\end{array}$ & no rxn & 6.8 \\
\hline $\begin{array}{l}\text { Neat TNAZ } \\
\text { (C168) }\end{array}$ & & 28 & 0.049 & $\begin{array}{l}\text { m.p. } \approx 96.83 \\
\text { dec. } \approx 245\end{array}$ & no rxn & 11.6 \\
\hline HMX ref. & & 32 & $\leq 0.2$ & 270 & no rxn & 11.6 \\
\hline
\end{tabular}

a Formulations consist of listed wt\%'s of binders and the rest TNAZ.

b Theoretical maximum density.

c $2.5 \mathrm{~kg}$, Type $12 \mathrm{~A}, 35 \mathrm{mg}$ pressed pellets.

d Chemical reactivity test. $120^{\circ} \mathrm{C}$ for $22 \mathrm{~h}$ under $1 \mathrm{~atm} \mathrm{He}$.

e $10^{\circ} \mathrm{C} / \mathrm{min}$.

f $1 \mathrm{~J}$ with $510 \Omega$.

g BAM.

A pressing study was carried out with formulations RX-22-AT to-AY. All materials could be easily pressed to densities of $99 \%$ at $200 \mathrm{kPa}$ and $60^{\circ} \mathrm{C}$. More work is required before these formulations could be consider optimized. The production of larger quantities of materials awaits further guidance from ARDEC.

\section{Conclusions}

The small-scale safety properties are similar but more sensitive than those observed with HMX. Violent reactions were seen in the ODTX experiments at times-toexplosion similar to RDX and $\varepsilon-C L-20$. However, the critical temperature in the ODTX configuration is almost as high as that of TNT. The energy of detonation was found to be $4 \%$ less than HMX. Shock loading studies showed TNAZ to be more sensitive than the similar energy density formulation of LX-14. The initiation behavior cannot be described as either homogeneous or heterogeneous. 


\section{Acknowledgments}

We would like to thank Dr. T. Archibald of GenCorp Aerojet for providing our first sample of TNAZ. Drs. G. Parsons and R. McKenney of the Wright Laboratory at Eglin Air Force Base, supplied material for larger scale experimentation. We would also like to thank Mr. S. Aubert, also at the Wright Laboratory, for numerous technical discussions concerning TNAZ.

\section{References}

1. T. G. Archibald, et al., Organic Chemistry, 55, 2920-2924 (1990).

2. S. A. Aubert, Wright Laboratory, U.S. Air Force, Eglin, Characterization of the Sensitivity and Performance of 1,3,3-Trinitroazetidine (TNAZ) (1994).

3. D. Stec III, R. Perez, S. Kerwien, On the Processing and Utilization of TNAZ, ADPA Symposium on Energetic Materials Technology (ADPA, Orlando, FL, 1994), pp. 6.

4. R.D. Chapman, J.W. Fronabarger, W.B. Sanborn, G. Burr, S. Knueppel, "Phase Behavior in TNAZ-based and Other Explosive Formulations," TPL-FR-2049, TPL, Inc. Albuquerque, NM 87109.

5. D. L. Ornellas, "Calorimetric Determinations of the Heat and Products of Detonation for Explosives: October 1961 to April 1982," Lawrence Livermore National Laboratory, UCRL-52821, 1982. 